\title{
Correction to: Spatiotemporal seismic excitation of bridges with an anti-symmetrical first mode
}

\author{
A. A. Meibodi ${ }^{1}$ (D) . N. A. Alexander ${ }^{1}$
}

Published online: 12 February 2021

(c) Springer Nature B.V. 2021

\section{Correction to: Bulletin of Earthquake Engineering https://doi.org/10.1007/s10518-020-01025-5}

This correction is published in order to inform that typesetter overlooked author corrections regarding older figures \& captions in the original publication.

Old version published which does not match the context of the paper.

Second, bold/non-bold for equations (15) onwards, were not inserted correctly.

Third, caption of Fig.10, should be subscript of sigma not in the line.

Original article has been updated.

Publisher's Note Springer Nature remains neutral with regard to jurisdictional claims in published maps and institutional affiliations.

The original article can be found online at https://doi.org/10.1007/s10518-020-01025-5.

\section{A. A. Meibodi}

arman.aghaeimeibodi@bristol.ac.uk

1 University of Bristol, Bristol, UK 